\title{
Fast Carbon Isotope Exchange of Carboxylic Acids Enabled by Organic Photoredox Catalysis
}

Duanyang Kong, ${ }^{\dagger}$ Maxime Munch, ${ }^{\ddagger}$ Qiqige Qiqige,$^{\dagger}$ Christopher J. C. Cooze, $^{\dagger}$ Benjamin H. Rotstein, ${ }^{*,}$ Rylan J. Lundgren*,

${ }^{\dagger}$ Department of Chemistry, University of Alberta, Edmonton, Alberta, T6G 2G2, Canada

‡ Departments of Biochemistry, Microbiology and Immunology and Departments of Chemistry and Biomolecular Sciences, University of Ottawa, Ottawa, Ontario, Canada K1H 8M5; University of Ottawa Heart Institute, Ottawa, Ontario, Canada K1Y 4W7

*rylan.lundgren@alberta.ca *Benjamin.Rotstein@uottawa.ca

Abstract Carbazole/cyanobenzene photocatalysts promote the direct isotopic carboxylate exchange of $\mathrm{C}\left(\mathrm{sp}^{3}\right)$-acids with labelled $\mathrm{CO}_{2}$. Substrates that are not compatible with transition metal catalyzed degradation-reconstruction approaches or prone to thermally induced reversible decarboxylation undergo isotopic incorporation at room temperature in short reaction times. The radiolabelling of drug molecules and precursors with $\left[{ }^{11} \mathrm{C}\right] \mathrm{CO}_{2}$ is demonstrated.

The synthesis of isotopically labelled molecules is essential to drug development and nuclear medicine. As drug candidates move towards clinical research and human trials, absorption, distribution, metabolism, and excretion (ADME) studies require compounds enriched with long-lived radioisotopes like ${ }^{3} \mathrm{H}$ and ${ }^{14} \mathrm{C}$. ${ }^{1}$ Positron emission tomography (PET) techniques that probe the advance of disease states and can determine the efficacy of drug treatment require molecular targets radiolabelled with short-lived positron-emitting isotopes such as ${ }^{11} \mathrm{C}$ or ${ }^{18} \mathrm{~F} .{ }^{2}$ The limited availability and high cost of isotopically enriched precursors make the preparation of complex targets challenging. For PET studies, compounds must be synthesized and purified within a few half-lives of the radiolabel $\left({ }^{11} \mathrm{C} \mathrm{t}_{1 / 2}=20.3\right.$ minutes). Approaches that selectively introduce isotopic labels from feedstock sources with compatibility towards common structural motifs found in clinical candidates will have a positive impact on both drug discovery efforts and medical imaging.

Metal-catalyzed ${ }^{1} \mathrm{H} /{ }^{3} \mathrm{H}$ exchange is widely used in drug development to introduce long-lived radiolabels into target molecules. ${ }^{3-9}$ The loss of ${ }^{3} \mathrm{H}$ labels through (bio)chemical reactions and metabolic shifting due to primary kinetic isotope effects are liabilities of ${ }^{3} \mathrm{H}$-labelling approachs. ${ }^{10-11}$ ADME tracer compounds with greater stability can be obtained by using ${ }^{14} \mathrm{C}$ radiolabels. ${ }^{12}$ Similarly, ${ }^{11} \mathrm{C}$-isotopologues of native bioactive molecules enable PET probe generation without changes to their biological or 
pharmacological properties. ${ }^{13}$ The incorporation of ${ }^{14} \mathrm{C},{ }^{13} \mathrm{C}$ or ${ }^{11} \mathrm{C}\left({ }^{*} \mathrm{C}\right)$ units into drug molecules or precursors by the formation of a ${ }^{*} \mathrm{C}-\mathrm{C}$ bond is challenging and often requires revised synthetic pathways to introduce the label from ${ }^{*} \mathrm{CO},{ }^{14-18}{ }^{*} \mathrm{CH}_{3},{ }^{19-20}$ or other small molecules derived by reduction of ${ }^{*} \mathrm{CO}_{2}$. ${ }^{21-}$ ${ }^{25}$ The direct exchange of carboxylate groups with $\mathrm{CO}_{2}$ offers the potential for simple and cost-effective syntheses of C-labelled small molecules, particularly as $\mathrm{CO}_{2}$ (or $\mathrm{BaCO}_{3}$ ) is the feedstock for all radiolabelled carbon-based precursors. ${ }^{26}$ The easy conversion of carboxylic acids into other common functionalities (esters, amides, ketones, alcohols) makes this an attractive tactic for isotope incorporation.

The use of redox active hydroxyphthalimide ester substrates in combination with Ni-based mediators and stoichiometric metal reductants enables carboxylate groups to undergo net exchange with $\mathrm{CO}_{2}$ (Fig 1A). ${ }^{27-28}$ These reactions are limited to primary alkyl or cyclic secondary alkyl acids lacking $\beta$-heteroatoms to achieve $>10 \%$ label incorporation. The requirements for long reaction times and use of large excesses of $\mathrm{CO}_{2}\left(\geq 16 \mathrm{~h}\right.$, often $>20$ equiv. $\left.\mathrm{CO}_{2}\right)$ make these methods incompatible for ${ }^{11} \mathrm{C}$ PET applications. $\mathrm{C}\left(\mathrm{sp}^{3}\right)$ acids that form stabilized carbanions upon ionic decarboxylation can undergo exchange with $\mathrm{CO}_{2}$ spontaneously at high temperatures in the solid state ${ }^{29}$ or in solution. ${ }^{30-32}$ (Fig $1 \mathrm{~A}$ ). In contrast, compounds that lack strong anion stabilizing groups like nitro- or cyanoaryl acetate groups require high reaction temperatures $\left(\geq 150^{\circ} \mathrm{C}\right.$ ), long reaction times ( $\geq 24$ hours), or are simply inert towards exchange. Audisio and co-workers demonstrated the ${ }^{11} \mathrm{C}$-labelling of the arylacetate drugs Flurbiprofen and Tolmetin by uncatalyzed exchange with $\left[{ }^{11} \mathrm{C}\right] \mathrm{CO}_{2}$, although slow kinetics and harsh conditions resulted in low radiochemical yields (RCY) $\left(7 \%\right.$ and $3 \%$ respectively at $\left.150{ }^{\circ} \mathrm{C}\right) .{ }^{30}$

With the goal of developing a mild method for direct carboxylate exchange at rates appropriate for ${ }^{11} \mathrm{C}$-labelling, we considered alternative strategies for $\mathrm{C}\left(\mathrm{sp}^{3}\right)$-carboxylate bond cleavage and subsequent $\mathrm{CO}_{2}$ recapture. Here we show that a family of organic photocatalysts mediate the exchange of $\mathrm{CO}_{2}$ groups without the need for prior stoichiometric carboxylate activation or high temperatures (Fig 1B). The radical-polar crossover process combines the advantages of low barrier $\mathrm{C}-\mathrm{CO}_{2}$ bond cleavage initiated by carboxylate single electron oxidation with the efficient, uncatalyzed recombination of carbanion intermediates with $\mathrm{CO}_{2} \cdot{ }^{33}$ Tertiary carboxylic acid substrates not compatible with either Nicatalysis or thermal reactions can be labelled to useful levels. The kinetics of $\mathrm{CO}_{2}$ exchange are compatible with ${ }^{11} \mathrm{C}$ labelling of nonsteroidal anti-inflammatory drugs (NSAIDs) and precursors to other bioactive molecules. 

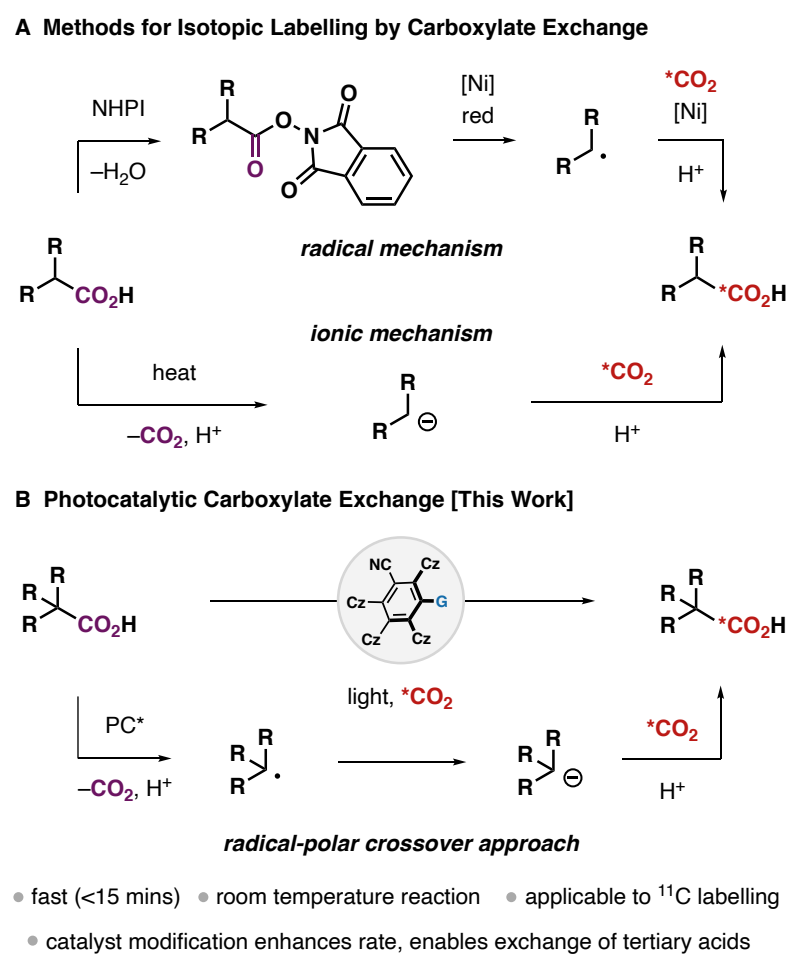

Figure 1. (A) Existing approaches for carboxylate $/ \mathrm{CO}_{2}$ exchange for isotopic labelling (NHPI = Nhydroxyphthalimide). (B) Fast, mild isotopic carboxylate exchange by organic photoredox catalysis (Cz = carbazole)

Photoredox catalysis can be used to induce decarboxylation by substrate single electron oxidation, however the recapture of $\mathrm{CO}_{2}$ under these conditions has not been reported. ${ }^{34-39}$ In considering new strategies for reversible decarboxylation of organic acids, we were inspired by Konig's studies ${ }^{40-41}$ which demonstrated that carbazole/dicyanobenzene based photocatalysts could mediate decarboxylative electrophile trapping by radical-polar crossover mechanisms. ${ }^{42}$ Upon surveying a wide array of organic and metal-based catalysts we found that $5 \mathrm{~mol} \% 4 \mathrm{CzIPN}^{43-44}$ enabled the isotopic labelling of Ibuprofen (1) with $\left[{ }^{13} \mathrm{C}_{\mathrm{CO}_{2}}\right.$ at room temperature upon irradiation with blue LEDs $\left(52 \%{ }^{13} \mathrm{C}\right.$ incorporation, $77 \%$ yield). Other donor-acceptor cyanoarenes or isomers of 4CzIPN performed poorly under similar conditions regardless of their redox properties (Fig $2 \mathrm{~A}$ ). ${ }^{45} \mathrm{Cs}_{2} \mathrm{CO}_{3}$ was the optimal base, although other bases could be used $\left(\mathrm{K}_{2} \mathrm{CO}_{3}, \mathrm{DBU}\right)$. DMA could be replaced with DMSO, but the use of less polar solvents (THF, MeCN) resulted in low ${ }^{13} \mathrm{C}$ incorporation (Fig $2 \mathrm{~A}$, see the SI for optimization details). Radical traps (TEMPO, BHT) completely inhibit reactivity. The exchange process remains efficient when using only 2 equivalents of $\left[{ }^{13} \mathrm{C}\right] \mathrm{CO}_{2}\left(43 \%{ }^{13} \mathrm{C}\right.$ incorporation, $75 \%$ yield).

Under standard reaction conditions alkylative decyanation of $4 \mathrm{CzIPN}$ occurs, ${ }^{40-41}$ this process is important to generating a more active catalyst. The direct use of benzylated catalyst $4 \mathrm{CzBnBN}$ (prepared by reacting $4 \mathrm{CzIPN}$ with phenylacetic acid) resulted in a pronounced increase in ${ }^{13} \mathrm{C}$ incorporation rates (Fig 2B). With 3 equivalents of $\left[{ }^{13} \mathrm{C}_{\mathrm{CO}_{2}}>40 \%\right.$ labelling of Ibuprofen was obtained in 10 minutes using 
A Effect of Catalyst and Reaction Conditions

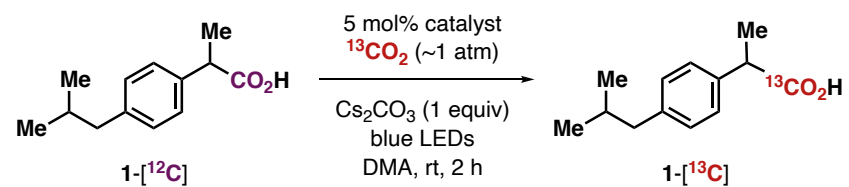

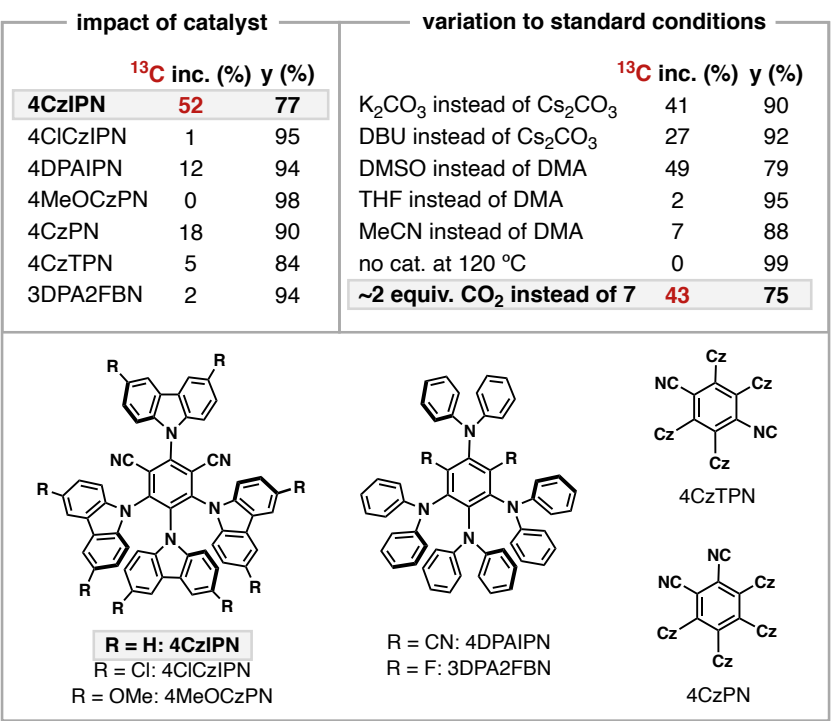

B Fast Exchange with Alkylated Catalyst
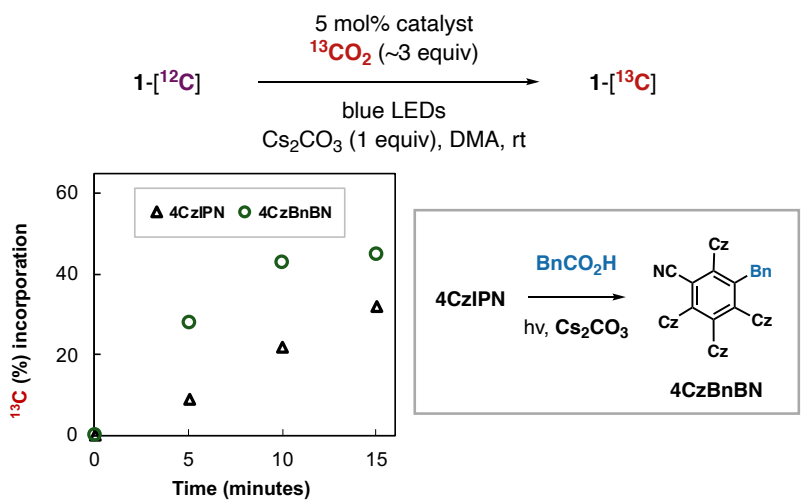

C Carboxylate Exchange with Tertiary Acids

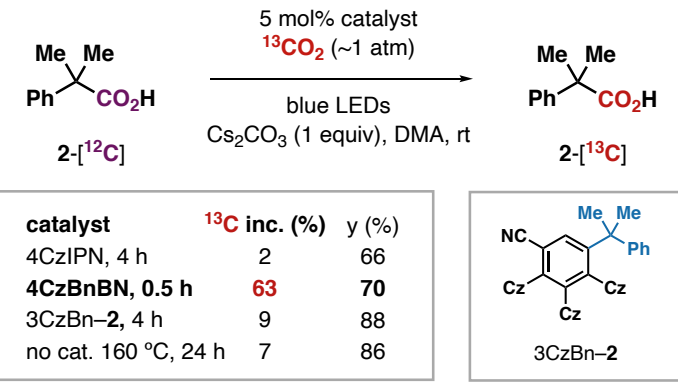

Figure 2. (A) Overview of photocatalyst effects and changes to reaction parameters. (B) $4 C z I P N$ and $4 \mathrm{CzBnBN}$ rate comparison for $\left[{ }^{13} \mathrm{C}\right] \mathrm{CO}_{2}$ exchange with lbuprofen. (C) $4 \mathrm{CzBnBN}$ enables carboxylate exchange with tertiary carboxylic acids.

$4 \mathrm{CzBnBN}$, which is double the incorporation observed with $4 \mathrm{CzIPN}$. $4 \mathrm{CzBnBN}$ enabled isotopic labelling of more challenging substrate classes. Tertiary acid 2 undergoes efficient labelling using $4 \mathrm{CzBnBN}(60 \%$ 
${ }^{13} \mathrm{C}$ incorporation, $70 \%$ yield), while low levels of exchange were detected using 4CzIPN (2\%). The difference in catalytic activity with tertiary substrates between these two catalysts can be rationalized by the observation that tertiary acid 2 reacts with $4 \mathrm{CzIPN}$ to give a carbazole elimination species $3 \mathrm{CzBn}-2$ (Fig 2C). 3CzBn-2 is a poor mediator of carboxylate exchange, likely owing to attenuated donor-acceptor properties. Catalyst screening studies showed little correlation between activity in carboxylate exchange and (pre)catalyst electrochemical potentials (see the SI for details). The selective generation of monoalkylated benzonitrile species under the reaction conditions appears to be the most important factor in dictating successful carboxylate exchange. For example, 4CICzIPN undergoes double benzylation in the presence of phenylacetic acid to generate an inactive species, while 4MeOCzIPN and 4DPAIPN are resistant to benzylation and perform sluggishly (Fig 2A, see the SI for details). These findings should have broader implications when designing and optimizing photocatalytic decarboxylative coupling reactions with donor-acceptor cyanoarenes.

With optimized reaction conditions, the scope and limitations of photoredox catalyzed carboxylate isotopic exchange were explored (Fig 3). For less challenging substrate classes, the commercially available 4CzIPN catalyst was used. Arylacetates, including those with halogens $(\mathbf{4}, \mathbf{5})$, moderate electron-withdrawing groups including amides (6), sulfonyls (7), $\mathrm{CF}_{3}$ groups (8), and Bpin units (9) underwent smooth carboxylate exchange. Electron-rich arylacetates with methoxy, thioether, or NHBoc groups $(10-13,21)$ also underwent ${ }^{13} \mathrm{C}$-labelling using the standard conditions. Heterocycles $(18,19)$ and more complex structures bearing potentially reactive ketone or phenol groups (20) were tolerated. Arylacetates substituted with $\alpha$-alkyl, $\alpha$-alkoxy, and $\alpha-\mathrm{NH}$ benzoyl groups were productive substrates (23-25), as were molecules featuring an alkene or terminal alkyne (26-27). Alkylated or heteroatom containing $\beta$-carboxy amides, $\beta$-carboxy lactams, malonate half-esters, and $\beta$-carboxy nitriles were compatible substrates (30-33). The labelling of complex molecules featuring malonate half-esters was possible (34-35). A series of tertiary carboxylic acids were isotopically labelled using $4 \mathrm{CzBnBN}$ as the catalyst, including $\alpha, \alpha$-dialkylated arylacetates (2, 37-39), fully substituted malonate half-esters (41), and carboxy lactams (42). These tertiary substrates do not undergo significant carboxylate exchange without catalyst under thermal conditions (see SI for details). Scope limitations include 4-OH or 4-SH containing arylacetates (15-16), simple alkyl acid 36, and the a-cyclopropyl acid $\mathbf{4 0 .}$

Photoredox catalyzed carboxylate exchange enables direct isotopic labelling of drug molecules and synthetic precursors under mild conditions. An array of NSAIDs underwent smooth exchange at room temperature, including those with potentially reactive functionalities and heterocyclic fragments (Fig 3, 43-50). Precursors to other classes of pharmaceuticals and clinical candidates that feature arylacetate units such as the acid of Zolpidem (51) or Pentoxyverine (52), and the core of VLA-4 


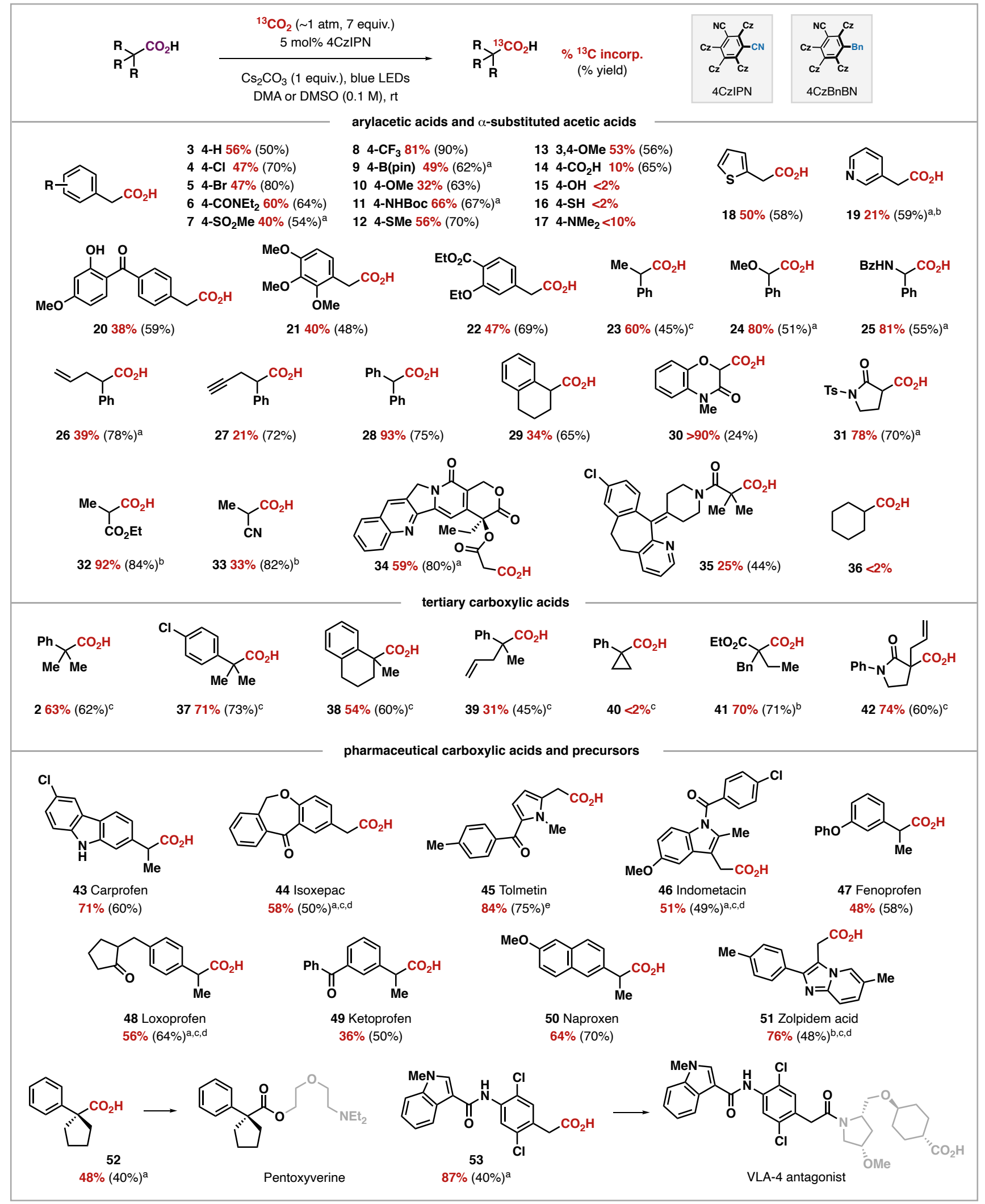

Figure 3. Scope and limitations. Unless noted yields are of isolated material. ${ }^{a}$ Calibrated ${ }^{1} \mathrm{H}$ NMR spectroscopy yield; ${ }^{b} \%{ }^{13} \mathrm{C}$ incorporation and yield determined after conversion to benzyl ester; ${ }^{\mathrm{c}} 5 \mathrm{~mol} \%$ $4 \mathrm{CzBnBN}$; ${ }^{\mathrm{d}} \sim 3$ equiv. $\left[{ }^{13} \mathrm{C}\right] \mathrm{CO}_{2},{ }^{\mathrm{e}} 2.5 \mathrm{~mol} \% 4 \mathrm{CzIPN}$. See the SI for details 
antagonist (53), ${ }^{46}$ could be labelled with good ${ }^{13} \mathrm{C}$-incorporation and yield. In the above cases replacement of $\left[{ }^{13} \mathrm{C}\right] \mathrm{CO}_{2}$ with $\left[{ }^{14} \mathrm{C}\right] \mathrm{CO}_{2}$ would allow for the preparation of compounds with specific activities suitable for most radiolabelling ADME studies $(37-300 \mathrm{mCi} / \mathrm{mg})$.

The rapid labelling of arylacetate drug molecules with $\left[{ }^{11} \mathrm{C} \mathrm{CO}_{2}\right.$ is feasible using a photocatalytic approach. ${ }^{47}\left[{ }^{11} \mathrm{C}\right]$ lbuprofen could be generated with $20 \%$ radiochemical yield (RCY) following 10 minutes of LED irradiation (Fig 4). Use of $4 \mathrm{CzBnBN}$ catalyst was essential for ${ }^{11} \mathrm{C}$-radiolabelling; no exchange was observed when using $4 \mathrm{CzIPN}$. Thermal conditions $\left(160^{\circ} \mathrm{C}\right)$ provided no radiolabeled product. Related targets Carprofen, Loxoprofen, and Fenoprofen could be radiolabelled under the standard conditions in $7-29 \%$ RCY, as could the tertiary acid substrate $52 .\left[{ }^{11} \mathrm{C}\right]$ Fenoprofen could be radiolabelled and isolated in 20 minutes starting from $\left[{ }^{11} \mathrm{C}^{-} \mathrm{CO}_{2}(\sim 2 \mathrm{GBq})\right.$ to give the product in $9.5 \%$ $\mathrm{RCY}$ and $>99 \%$ radiochemical purity with a molar activity of $0.029 \mathrm{GBq} / \mathrm{mmol}$ (Fig 4). This level of molar activity is consistent with isotopic exchange reactions and is useful for studying biodistribution processes.
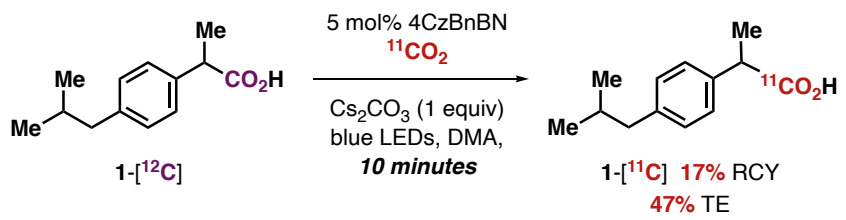

4CzIPN instead of $4 \mathrm{CzBnBN} 0 \% \mathrm{RCY}$ no catalyst, $160^{\circ} \mathrm{C} 0 \% \mathrm{RCY}$
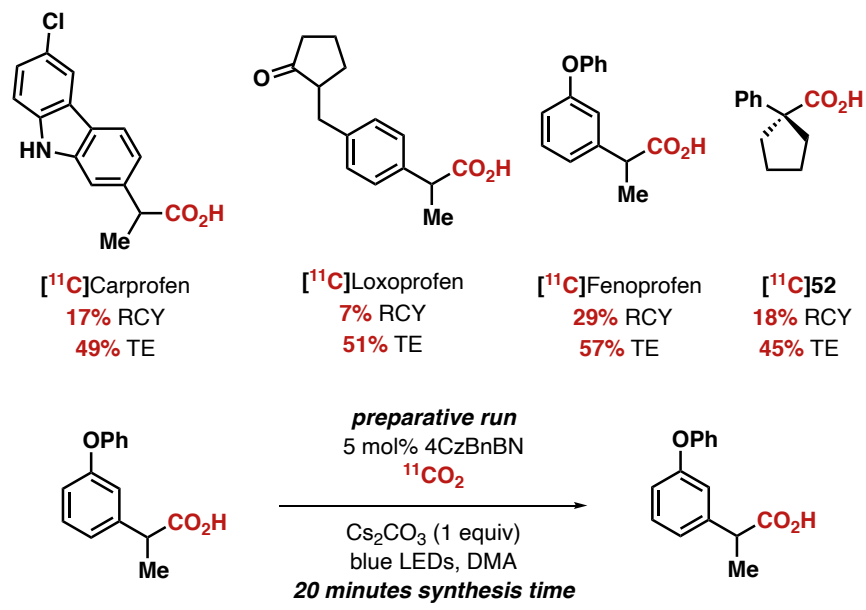

Fenprofen

Figure 4. Photoredox catalyzed carboxylate exchange with ${ }^{11} \mathrm{CO}_{2}(\mathrm{TE}=$ trapping efficiency of radioactivity in solution; $\mathrm{RCP}=$ radiochemical purity; RCY $=\mathrm{TE} \times \mathrm{RCP})$. 
In conclusion, organic photoredox catalysis enables a mild and rapid pathway for direct carboxylate exchange, including processes that use $\left[{ }^{11} \mathrm{C}\right] \mathrm{CO}_{2}$. The reaction conditions and substrate scope complement $\mathrm{Ni}$-catalyzed strategies for isotopic labelling of alkyl carboxylates using $\mathrm{CO}_{2}$. Compatibility with potentially reactive functional groups, heterocycles, and tertiary acids, combined with the opportunity to refine photocatalyst performance should provide an avenue for future use in radiolabelling applications.

\section{Acknowledgments}

Support was provided by NSERC Canada (RGPIN-2019-06050 and RGPAS-2019-00051 to R.J.L, RGPIN-2017-06167 to B.H.R., PGS-D fellowship for C.J.C.C) the Canadian Foundation for Innovation (IOF 32691 to R.J.L, JELF 36848 to B.H.R.), the University of Alberta, the Province of Alberta (AGES fellowship to C.J.C.C.), and the Province of Ontario (ER17-13-119).

\section{References}

1. Elmore, C. S.; Bragg, R. A., Isotope chemistry; a useful tool in the drug discovery arsenal. Bioorg. Med. Chem. Lett. 2015, 25 (2), 167-171.

2. Deng, X.; Rong, J.; Wang, L.; Vasdev, N.; Zhang, L.; Josephson, L.; Liang, S. H., Chemistry for Positron Emission Tomography: Recent Advances in ${ }^{11} \mathrm{C}-,{ }^{18} \mathrm{~F}-,{ }^{13} \mathrm{~N}$-, and ${ }^{15} \mathrm{O}$-Labeling Reactions. Angew. Chem. Int. Ed. 2019, 58 (9), 2580-2605.

3. For a review see: Lockley, W. J. S.; McEwen, A.; Cooke, R., Tritium: a coming of age for drug discovery and development ADME studies. J. Label. Compd. Radiopharm. 2012, 55 (7), 235-257.

4. Kerr, W. J.; Knox, G. J.; Reid, M.; Tuttle, T.; Bergare, J.; Bragg, R. A., Computationally-Guided Development of a Chelated NHC-P Iridium(I) Complex for the Directed Hydrogen Isotope Exchange of Aryl Sulfones. ACS Catal. 2020, 10 (19), 11120-11126.

5. Zarate, C.; Yang, H.; Bezdek, M. J.; Hesk, D.; Chirik, P. J., Ni(I)-X Complexes Bearing a Bulky aDiimine Ligand: Synthesis, Structure, and Superior Catalytic Performance in the Hydrogen Isotope Exchange in Pharmaceuticals. J. Am. Chem. Soc. 2019, 141 (12), 5034-5044.

6. Atzrodt, J.; Derdau, V.; Kerr, W. J.; Reid, M., Deuterium- and Tritium-Labelled Compounds: Applications in the Life Sciences. Angew. Chem. Int. Ed. 2018, 57 (7), 1758-1784.

7. Koniarczyk, J. L.; Hesk, D.; Overgard, A.; Davies, I. W.; McNally, A., A General Strategy for SiteSelective Incorporation of Deuterium and Tritium into Pyridines, Diazines, and Pharmaceuticals. J. Am. Chem. Soc. 2018, 140 (6), 1990-1993.

8. Loh, Y. Y.; Nagao, K.; Hoover, A. J.; Hesk, D.; Rivera, N. R.; Colletti, S. L.; Davies, I. W.; MacMillan, D. W. C., Photoredox-catalyzed deuteration and tritiation of pharmaceutical compounds. Science 2017, 358 (6367), 1182-1187.

9. Pony Yu, R.; Hesk, D.; Rivera, N.; Pelczer, I.; Chirik, P. J., Iron-catalysed tritiation of pharmaceuticals. Nature 2016, 529 (7585), 195-199.

10. Krauser, J. A., A perspective on tritium versus carbon-14: ensuring optimal label selection in pharmaceutical research and development. J. Label. Compd. Radiopharm. 2013, 56 (9-10), 441-446. 
11. Elmore, C. S., The Use of Isotopically Labeled Compounds in Drug Discovery. In Annu. Rep. Med. Chem., Macor, J. E., Ed. Academic Press: 2009; Vol. 44, 515-534.

12. Penner, N.; Klunk, L. J.; Prakash, C., Human radiolabeled mass balance studies: objectives, utilities and limitations. Biopharm. Drug Dispos. 2009, 30 (4), 185-203.

13. Rotstein, B. H.; Liang, S. H.; Placzek, M. S.; Hooker, J. M.; Gee, A. D.; Dollé, F.; Wilson, A. A.; Vasdev, N., ${ }^{11} \mathrm{C}-\mathrm{O}$ bonds made easily for positron emission tomography radiopharmaceuticals. Chem. Soc. Rev. 2016, 45 (17), 4708-4726.

14. Donslund, A. S.; Pedersen, S. S.; Gaardbo, C.; Neumann, K. T.; Kingston, L.; Elmore, C. S.; Skrydstrup, T., Direct Access to Isotopically Labeled Aliphatic Ketones Mediated by Nickel(I) Activation. Angew. Chem. Int. Ed. 2020, 59 (21), 8099-8103.

15. Pedersen, S. K.; Gudmundsson, H. G.; Nielsen, D. U.; Donslund, B. S.; Hammershøj, H. C. D.; Daasbjerg, K.; Skrydstrup, T., Main element chemistry enables gas-cylinder-free hydroformylations. Nat. Catal. 2020, 3, 843-850.

16. Ravn, A. K.; Vilstrup, M. B. T.; Noerby, P.; Nielsen, D. U.; Daasbjerg, K.; Skrydstrup, T., Carbon Isotope Labeling Strategy for $\beta$-Amino Acid Derivatives via Carbonylation of Azanickellacycles. J. Am. Chem. Soc. 2019, 141 (30), 11821-11826.

17. Gauthier, D. R.; Rivera, N. R.; Yang, H.; Schultz, D. M.; Shultz, C. S., Palladium-Catalyzed Carbon Isotope Exchange on Aliphatic and Benzoic Acid Chlorides. J. Am. Chem. Soc. 2018, 140 (46), 1559615600.

18. Nielsen, D. U.; Neumann, K. T.; Lindhardt, A. T.; Skrydstrup, T., Recent developments in carbonylation chemistry using $\left[{ }^{13} \mathrm{C}\right] \mathrm{CO},\left[{ }^{11} \mathrm{C}\right] \mathrm{CO}$, and $\left[{ }^{14} \mathrm{C}\right] \mathrm{CO}$. J. Label. Compd. Radiopharm. 2018, 61 (13), 949-987.

19. Gauthier, D. R.; Yoshikawa, N., A General, One-Pot Method for the Synthesis of Sulfinic Acids from Methyl Sulfones. Org. Lett. 2016, 18 (23), 5994-5997.

20. Piecyk, K.; Davis, R. E.; Jankowska-Anyszka, M., Synthesis of ${ }^{13} \mathrm{C}$ - and ${ }^{14} \mathrm{C}$-labeled dinucleotide mRNA cap analogues for structural and biochemical studies. Bioorg. Med. Chem. Lett. 2012, 22 (13), 4391-4395.

21. Maxwell, B. D.; Tran, S. B.; Lago, M.; Li, J.; Bonacorsi Jr., S. J., The syntheses of $\left[{ }^{14} \mathrm{C}\right] \mathrm{BMS}-823778$ for use in a human ADME clinical study and of $\left[{ }^{13} \mathrm{CD}_{3}{ }^{13} \mathrm{CD}_{2}\right] \mathrm{BMT}-094817$, a stable-isotope labeled standard of a newly detected human metabolite. J. Label. Compd. Radiopharm. 2016, 59 (6), 255-259.

22. Ren, S.; Gauthier, D.; Marques, R.; Helmy, R.; Hesk, D., Synthesis of $\left[{ }^{14}\right.$ C]omarigliptin. J. Label. Compd. Radiopharm. 2016, 59 (10), 386-390.

23. Lee, H. G.; Milner, P. J.; Placzek, M. S.; Buchwald, S. L.; Hooker, J. M., Virtually Instantaneous, Room-Temperature $\left[{ }^{11} \mathrm{C}\right]$-Cyanation Using Biaryl Phosphine $\mathrm{Pd}(0)$ Complexes. J. Am. Chem. Soc. 2015, 137 (2), 648-651.

24. Ekhato, I. V.; Bonacorsi Jr, S., The synthesis of radiolabeled Irbesartan using N,Ndimethyl $\left[{ }^{14} \mathrm{C}\right]$ formamide as a source of carbon-14 isotope. J. Label. Compd. Radiopharm. 2011, 54 (4), 202-205.

25. Cao, K.; Bonacorsi Jr, S. J.; Balasubramanian, B.; Hanson, R. L.; Manchand, P.; Godfrey Jr, J. D.; Fox, R.; Christopher, L. J.; Su, H.; lyer, R., Carbon-14 labeling of Saxagliptin (BMS-477118). J. Label. Compd. Radiopharm. 2007, 50 (13), 1224-1229.

26. Hinsinger, K.; Pieters, G., The Emergence of Carbon Isotope Exchange. Angew. Chem. Int. Ed. 2019, 58 (29), 9678-9680. 
27. Kingston, C.; Wallace, M. A.; Allentoff, A. J.; deGruyter, J. N.; Chen, J. S.; Gong, S. X.; Bonacorsi, S.; Baran, P. S., Direct Carbon Isotope Exchange through Decarboxylative Carboxylation. J. Am. Chem. Soc. 2019, 141 (2), 774-779.

28. Tortajada, A.; Duan, Y.; Sahoo, B.; Cong, F.; Toupalas, G.; Sallustrau, A.; Loreau, O.; Audisio, D.; Martin, R., Catalytic Decarboxylation/Carboxylation Platform for Accessing Isotopically Labeled Carboxylic Acids. ACS Catal. 2019, 9 (7), 5897-5901.

29. Szabolcs, A.; Szammer, J.; Noszkó, L., A new method for the preparation of carboxyl-labelled aliphatic carboxylic acids. Tetrahedron 1974, 30 (19), 3647-3648.

30. Destro, G.; Horkka, K.; Loreau, O.; Buisson, D. A.; Kingston, L.; Del Vecchio, A.; Schou, M.; Elmore, C. S.; Taran, F.; Cantat, T.; Audisio, D., Transition-Metal-Free Carbon Isotope Exchange of Phenyl Acetic Acids. Angew. Chem. Int. Ed. 2020, 59 (32), 13490-13495.

31. Kong, D.; Moon, P. J.; Lui, E. K. J.; Bsharat, O.; Lundgren, R. J., Direct reversible decarboxylation from stable organic acids in dimethylformamide solution. Science 2020, 369 (6503), 557-561.

32. Destro, G.; Loreau, O.; Marcon, E.; Taran, F.; Cantat, T.; Audisio, D., Dynamic Carbon Isotope Exchange of Pharmaceuticals with Labeled $\mathrm{CO}_{2}$. J. Am. Chem. Soc. 2019, 141 (2), 780-784.

33. Li, Z.; Mayer, R. J.; Ofial, A. R.; Mayr, H., From Carbodiimides to Carbon Dioxide: Quantification of the Electrophilic Reactivities of Heteroallenes. J. Am. Chem. Soc. 2020, 142 (18), 8383-8402.

34. Romero, N. A.; Nicewicz, D. A., Organic Photoredox Catalysis. Chem. Rev. 2016, 116 (17), 1007510166.

35. Shaw, M. H.; Twilton, J.; MacMillan, D. W. C., Photoredox Catalysis in Organic Chemistry. J. Org. Chem. 2016, 81 (16), 6898-6926.

36. Crespi, S.; Fagnoni, M., Generation of Alkyl Radicals: From the Tyranny of Tin to the Photon Democracy. Chem. Rev. 2020, 120 (17), 9790-9833.

37. For photoredox carboxylation via $\mathrm{CO}_{2}$ activation see: Seo, $\mathrm{H}$.; Katcher, M. H.; Jamison, T. F., Photoredox activation of carbon dioxide for amino acid synthesis in continuous flow. Nat. Chem. 2017, 9 (5), 453-456.

38. Zhang, Z.; Ye, J.-H.; Ju, T.; Liao, L.-L.; Huang, H.; Gui, Y.-Y.; Zhou, W.-J.; Yu, D.-G., Visible-LightDriven Catalytic Reductive Carboxylation with $\mathrm{CO}_{2}$. ACS Catal. 2020, 10 (19), 10871-10885.

39. Yeung, C. S., Photoredox Catalysis as a Strategy for $\mathrm{CO}_{2}$ Incorporation: Direct Access to Carboxylic Acids from a Renewable Feedstock. Angew. Chem. Int. Ed. 2019, 58 (17), 5492-5502.

40. Donabauer, K.; Maity, M.; Berger, A. L.; Huff, G. S.; Crespi, S.; König, B., Photocatalytic carbanion generation - benzylation of aliphatic aldehydes to secondary alcohols. Chem. Sci. 2019, 10 (19), 51625166.

41. Meng, Q.-Y.; Schirmer, T. E.; Berger, A. L.; Donabauer, K.; König, B., Photocarboxylation of Benzylic C-H Bonds. J. Am. Chem. Soc. 2019, 141 (29), 11393-11397.

42. Pitzer, L.; Schwarz, J. L.; Glorius, F., Reductive radical-polar crossover: traditional electrophiles in modern radical reactions. Chem. Sci. 2019, 10 (36), 8285-8291.

43. Shang, T.-Y.; Lu, L.-H.; Cao, Z.; Liu, Y.; He, W.-M.; Yu, B., Recent advances of 1,2,3,5tetrakis(carbazol-9-yl)-4,6-dicyanobenzene (4CzIPN) in photocatalytic transformations. Chem. Commun. 2019, 55 (38), 5408-5419.

44. Uoyama, H.; Goushi, K.; Shizu, K.; Nomura, H.; Adachi, C., Highly efficient organic light-emitting diodes from delayed fluorescence. Nature 2012, 492 (7428), 234-238. 
45. Speckmeier, E.; Fischer, T. G.; Zeitler, K., A Toolbox Approach to Construct Broadly Applicable Metal-Free Catalysts for Photoredox Chemistry: Deliberate Tuning of Redox Potentials and Importance of Halogens in Donor-Acceptor Cyanoarenes. J. Am. Chem. Soc. 2018, 140 (45), 15353-15365.

46. Muro, F.; limura, S.; Sugimoto, Y.; Yoneda, Y.; Chiba, J.; Watanabe, T.; Setoguchi, M.; ligou, Y.; Matsumoto, K.; Satoh, A.; Takayama, G.; Taira, T.; Yokoyama, M.; Takashi, T.; Nakayama, A.; Machinaga, N., Discovery of trans-4-[1-[[2,5-Dichloro-4-(1-methyl-3-indolylcarboxamido)phenyl]acetyl](4S)-methoxy-(2S)-pyrrolidinylmethoxy]cyclohexanecarboxylic Acid: An Orally Active, Selective Very Late Antigen-4 Antagonist. J. Med. Chem. 2009, 52 (24), 7974-7992.

47. For a review on ${ }^{11} \mathrm{CO}_{2}$ use in PET applications see: (a) Taddei, C.; Gee, A. D., Recent progress in $\left[{ }^{11} \mathrm{C}\right]$ carbon dioxide $\left(\left[{ }^{11} \mathrm{C}\right] \mathrm{CO}_{2}\right)$ and $\left[{ }^{11} \mathrm{C}\right]$ carbon monoxide $\left(\left[{ }^{11} \mathrm{C}\right] \mathrm{CO}\right)$ chemistry. J. Label. Compd. Radiopharm. 2018, 61 (3), 237-251; For examples of the preparation of ${ }^{11} \mathrm{C}-\mathrm{NSA}$ IDs by methylation methods see: (b) Takashima-Hirano, M.; Shukuri, M.; Takashima, T.; Goto, M.; Wada, Y.; Watanabe, Y.; Onoe, H.; Doi, H.; Suzuki, M., General Method for the ${ }^{11} \mathrm{C}$-Labeling of 2-Arylpropionic Acids and Their Esters: Construction of a PET Tracer Library for a Study of Biological Events Involved in COXs Expression. Chem. Eur. J. 2010, 16 (14), 4250-4258; (c) Qu, W.; Hu, B.; Babich, J. W.; Waterhouse, N.; Dooley, M.; Ponnala, S.; Urgiles, J., A general ${ }^{11} \mathrm{C}$-labeling approach enabled by fluoride-mediated desilylation of organosilanes. Nat. Commun. 2020, 11 (1), 1736. 